\title{
Low transverse incision for lateral neck dissection in patients with papillary thyroid cancer: improved cosmesis
}

\author{
Chang Myeon Song ${ }^{1}$, Yong Bae Ji ${ }^{1}$ In Sik Kim', Ji Young Lee ${ }^{2}$, Dong Sun Kim³ and Kyung Tae ${ }^{1 *}$
}

\begin{abstract}
Background: Various incisions and approaches have been developed for lateral neck dissection. The purpose of this study was to compare the surgical and cosmetic outcomes of a single low transverse incision with the hockey stick incision for lateral neck dissection (LND) in patients with papillary thyroid carcinoma (PTC).

Methods: We retrospectively analyzed 97 patients with PTC who underwent therapeutic LND and total thyroidectomy by low transverse incision (62 patients) or hockey stick incision (35 patients). We compared the operative results, cosmetic outcomes, objective scar measurement, and sensory disturbance between the two groups.

Results: The number of harvested and metastatic lymph nodes, Vancouver Scar Scale scores, and sensory change were not significantly different between the two groups. The mean number of harvested lymph nodes in level II was 9.82 vs. $9.63(P=0.885)$ (transverse incision vs. hockey stick incision, respectively) and in level $\vee$ was 6.36 vs. $5.63(P=0.597)$.

However, subjective satisfaction with the scar and neck contour was higher in the low transverse incision group compared with the hockey stick incision group. Scores for scar consciousness and sensory change were not significantly different between the two groups.
\end{abstract}

Conclusions: A single low transverse incision may provide equivalent surgical outcomes and superior cosmetic outcomes compared with the hockey stick incision for LND in PTC.

Keywords: Papillary thyroid carcinoma, Incision, Lateral neck dissection, Selective neck dissection, Lymph node dissection

\section{Background}

The incidence of papillary thyroid carcinoma (PTC) is increasing due to advances in screening modalities, including ultrasonography [1]. Although PTC has a good prognosis, cervical lymph node metastasis is frequently detected, which increases locoregional recurrence and decreases survival, particularly when the metastasis is in the lateral compartment lymph node [2, 3]. Therapeutic lateral neck dissection (LND) should be performed in patients with PTC when lymph node metastasis is in the lateral compartment [4]. The compartment-oriented en bloc neck dissection is favored over a "berry-picking procedure" for lateral compartment node metastasis.

\footnotetext{
* Correspondence: kytae@hanyang.ac.kr

${ }^{1}$ Department of Otolaryngology-Head and Neck Surgery, College of Medicine, Hanyang University, 222 Wangsimni-ro, Seongdong-gu, Seoul 04763, South Korea

Full list of author information is available at the end of the article
}

The extent of LND includes modified radical neck dissection (MRND), selective neck dissection including levels II, III, IV, and V, or super-selective neck dissection [5].

Several types of incision can be used for LND of patients with PTC, including a hockey stick incision, an apron incision, a single transverse incision, a modified MacFee incision, or a modified Schobinger incision [6, 7]. In practice, the most commonly used incisions are the hockey stick incision, the modified MacFee incision, and the low transverse incision. A hockey stick incision provides excellent access to neck levels I and II, but invades the relaxed skin-tension line and can result in scar hypertrophy [8]. A single low transverse incision is parallel to, and does not invade, the relaxed skin-tension line, and therefore usually favors a good postoperative scar. However, access to the upper neck levels, including levels I and II might be more difficult with low transverse incision than with other 
incisions due to the increased distance from the incision site. These days most surgeons prefer to use a transverse incision, with or without modifications, for LND in patients with PTC due to the potential advantage of superior cosmesis. However, the efficacy of a low single transverse incision for LND has not yet been evaluated in comparison with other incision approaches.

In the current study, we compared surgical outcomes, including objective scar assessment, subjective cosmetic satisfaction, sensory change, lymph node yield, and surgical completeness, between low transverse incisions and hockey stick incisions following LND for patients with PTC and lateral compartment node metastasis.

\section{Methods}

We analyzed the data of 97 patients with PTC who underwent unilateral therapeutic selective neck dissection with total thyroidectomy and central neck dissection in a tertiary hospital by a single surgeon (K.T.) between January 2010 and September 2014. Our eligibility criteria included patients with PTC who had undergone unilateral therapeutic lateral compartment neck dissection with concomitant total thyroidectomy, whose pathologic results confirmed lateral compartment lymph node metastasis, and who had completed both a scar assessment and a questionnaire to evaluate cosmetic satisfaction and sensory change. We excluded patients who had undergone bilateral LND and those with other pathologic types of thyroid cancer, distant metastasis, recurrent tumor, or a history of previous neck irradiation or neck surgery.

Of the 97 patients, 62 patients underwent LND by single low transverse incision, and 35 patients by L-shaped hockey stick incision. No randomization was performed between the two groups. The choice of skin incision was mainly decided according to surgeon's preference and patient status.
In our institution, a hockey stick incision is a transverse incision one finger-breadth above the suprasternal notch with an extension superiorly lateral to the posterior border of the sternocleidomastoid muscle, reaching the mastoid tip (Fig. 1a, b). A single low transverse incision is placed one finger-breadth above the suprasternal notch and extends parallel to the skin-tension line from the medial border of the contralateral sternocleidomastoid muscle to the anterior border of the ipsilateral trapezius muscle (Fig. 2a, b).

In our department, neck levels II to V were routinely dissected in most patients undergoing LND. Level I was not dissected unless there was suspicious lymph node metastasis. Neck levels IIb and Va were also not dissected in some patients with either no suspicious lymph nodes in level IIa or single-level lymph node metastasis in preoperative imaging or intraoperative finding. We did not perform prophylactic LND for patients with PTC who were clinically negative in the lateral compartment. The lateral compartment lymph node specimens removed were classified according to nodal level, including the sublevels IIa, IIb, Va, and Vb. In all cases, the platysma layers and subcutaneous tissue layers of the upper and lower skin flap were sutured with an absorbable polyglactic acid suture material $\left(4.0\right.$ Vicryl $^{\mathrm{TM}}$; Ethicon, Inc.), and skin closure was performed with a non-absorbable monofilament Nylon suture (5.0 Ethilon $^{\mathrm{TM}}$, Ethicon, Inc.). All non-absorbable sutures were removed 6 days after the operation.

We compared the demographics, tumor characteristics, surgical outcomes (including operative time, amount of drainage, perioperative complications, number of harvested, and metastatic lymph nodes according to neck levels), level of thyroid-stimulating hormone (TSH)-stimulated serum thyroglobulin (Tg), and iodine uptake in a whole-body iodine scan between the two groups. Postoperative radioactive iodine (RAI) ablation

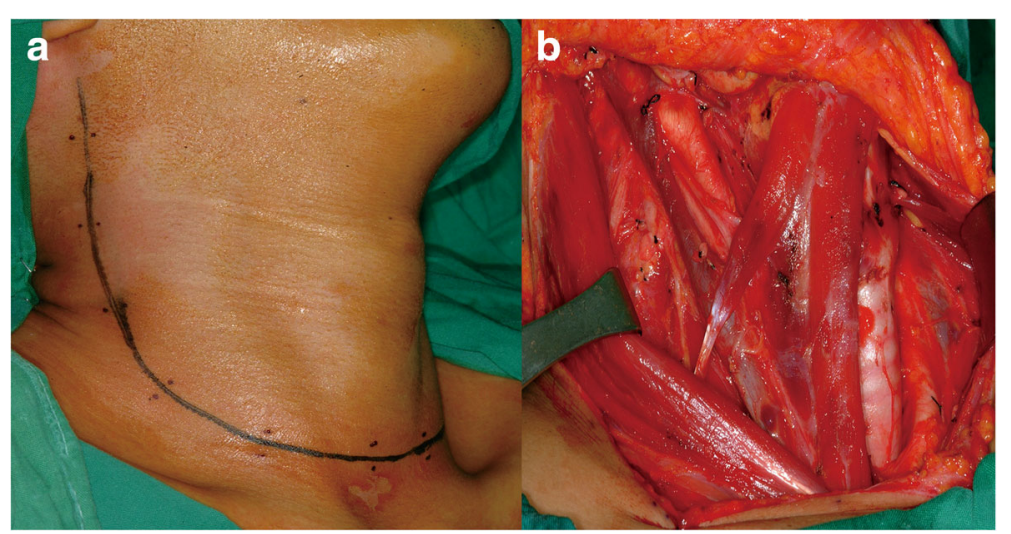

Fig. 1 Hockey stick incision for right lateral neck dissection. a The incision is composed of a low transverse incision and a vertical extension superiorly reaching the mastoid tip. $\mathbf{b}$ The surgical view of the entire neck, including upper neck levels I and II 


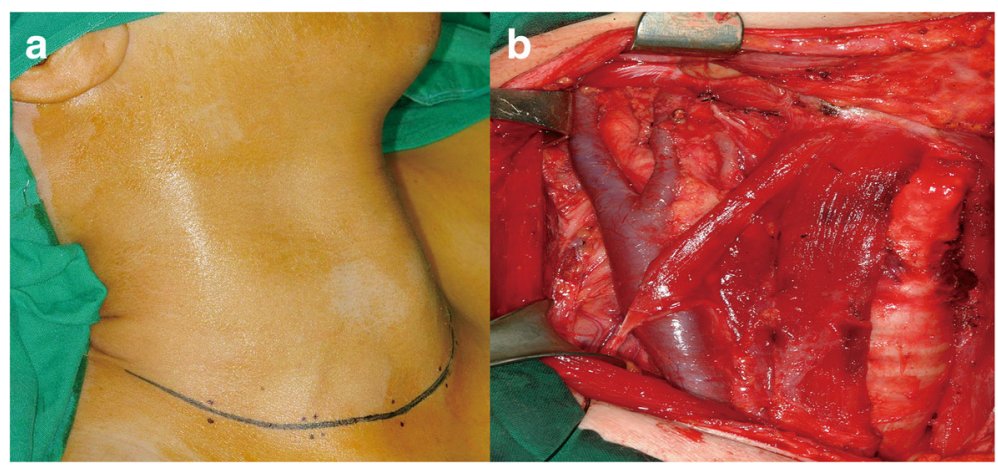

Fig. 2 Single low transverse incision for right lateral neck dissection. a The incision is located one finger-breadth above the suprasternal notch and parallel to the skin-tension line, from the medial border of the contralateral sternocleidomastoid muscle to the anterior border of the ipsilateral trapezius muscle. b The surgical view after total thyroidectomy and lateral neck dissection: complete dissection of levels II to $\mathrm{V}$ is possible

was performed 2-4 months after surgery using a dose of 30-150 mCi. A diagnostic RAI whole-body scan was performed 6-12 months after the first RAI ablation with a dose of 2-30 $\mathrm{mCi}$ both with and without a therapeutic purpose. TSH-stimulated serum Tg level was measured during RAI ablation and during a diagnostic whole-body iodine scan.

A scar was analyzed objectively using the Vancouver Scar Scale (VSS) at 12-24 months postoperatively. VSS is a validated objective scar scale that is commonly used in clinical studies [9]. VSS assesses four domains: vascularity, pigmentation, pliability, and height of the scar [10]. Vascularity, pigmentation, and height of the scar are scored from 0 to 3 , and pliability is scored from 0 to 5 . The score is the sum of four domains, with a score of 0 representing normal skin and a score of 14 representing the worst scar [11].

Subjective cosmetic satisfaction and consciousness of scar were evaluated at the same time as VSS using an author-developed questionnaire. Cosmetic satisfaction was assessed with two questions: (1) How satisfied are you with the neck scar? (2) How satisfied are you with the contour of the neck? Each question was scored as 0 (very satisfied), 1 (satisfied), 2 (average), 3 (dissatisfied), and 4 (very dissatisfied) [11]. Scar consciousness was assessed with four questions: (1) Do you think others look at your neck scar? (2) Do you try to conceal your scar? (3) Does your neck scar influence your choice of clothes? (4) How often do you think of your scar? Each question was scored as 0 (never), 1 (sometimes), 2 (frequently), or 3 (always) [11]. Total cosmetic satisfaction score was defined as the sum of the scores for cosmetic satisfaction (two questions) plus the sum of the scores for scar consciousness (four questions).

Sensory change was evaluated at the same time using a questionnaire in which patients were asked if they have any hypesthesia or paresthesia in the neck: Do you have decreased sensation or paresthesia in your neck area [12]? Score of sensory change ranged from 0 (none) to 4 (severe). All VSS assessments and the questionnaires for cosmesis and sensory disturbance were conducted by the same head-and-neck oncology nurse coordinator.

Differences in continuous variables were analyzed with the Student's $t$ test. Differences in categorical variables were analyzed with the chi-squared test or Fisher's exact test when the cell size was small. All statistical analyses were performed using SPSS version 21.0 (SPSS Chicago, IL). A $P$ value $<0.05$ was considered statistically significant.

\section{Results}

Demographics and tumor characteristics are listed in Table 1. Age and gender of the patients were not significantly different between patients in the transverse incision group and those in the hockey stick incision group. Primary tumor size, rates of multiple and bilateral tumor, minimal extrathyroidal extension, lymphovascular invasion, tumor $(\mathrm{T})$ and node $(\mathrm{N})$ classification, and tumor, node, metastasis (TNM) staging were not significantly different between the two groups.

Comparisons of the surgical outcomes between the two groups are summarized in Table 2. The extent of central and lateral neck dissection, operative time, and amount of drainage were not significantly different between the two groups. The rates of complications including hypoparathyroidism, vocal cord paralysis, hematoma, seroma, chyle leakage, and wound infection were not significantly different. There was no injury to the spinal accessory nerve, brachial plexus, or phrenic nerve in either group. The incidence of postoperative RAI ablation and the dose of RAI were not significantly different. TSH-stimulated serum Tg levels at the first RAI and at diagnostic whole-body iodine scan, and 
Table 1 Patient and tumor characteristics in patients with low transverse lateral incision and hockey stick incision

\begin{tabular}{llll}
\hline Parameter & $\begin{array}{l}\text { Transverse } \\
\text { Incision group } \\
n=62\end{array}$ & $\begin{array}{l}\text { Hockey stick } \\
\text { Incision group } \\
n=35\end{array}$ & $P$ value \\
\hline Age & $47.2 \pm 13.3$ & $46.7 \pm 14.6$ & .866 \\
Gender & & & \\
$\quad$ Female & $41 / 62(66.1 \%)$ & $22 / 35(62.9 \%)$ & .826 \\
Size of tumor (mm) & $19.3 \pm 13.5$ & $24.1 \pm 16.5$ & .129 \\
Multiplicity of tumor & $33 / 62(53.2 \%)$ & $12 / 35(34.3 \%)$ & .091 \\
Bilaterality of tumor & $20 / 62(32.3 \%)$ & $11 / 35(31.4 \%)$ & .560 \\
Minimal ETE & $30 / 62(48.4 \%)$ & $19 / 35(54.3 \%)$ & .674 \\
Lymphovascular invasion & $28 / 62(45.2 \%)$ & $22 / 35(62.9 \%)$ & .138 \\
T classification & & & .194 \\
T1 & $18(29.0 \%)$ & $5(14.3 \%)$ & \\
T2 & $2(3.2 \%)$ & $4(11.4 \%)$ & \\
T3 & $41(66.1 \%)$ & $24(68.6 \%)$ & \\
T4 & $1(1.6 \%)$ & $2(5.7 \%)$ & \\
N classification & & & \\
N1b & $62(100 \%)$ & $35(100 \%)$ & \\
TNM stage & & & \\
I & $29(47.5 \%)$ & $17(48.6 \%)$ & \\
II & $0(0 \%)$ & $0(0 \%)$ & \\
III & $31(50.8 \%)$ & $16(45.7 \%)$ & \\
IV & $1(1.6 \%)$ & $2(5.7 \%)$ & \\
\hline
\end{tabular}

ETE extrathyroidal extension, NA not applicable

uptake outside the thyroid bed on whole-body iodine scan were not significantly different between the two groups.

The numbers of harvested and metastatic lymph nodes are listed in Table 3. The number of harvested and metastatic lymph nodes was not significantly different in total, in the lateral compartment, or in each neck level including levels II, III, IV, V, and VI. The mean number of harvested lymph nodes in level II was 9.82 vs. $9.63(P=0.885)$ (transverse incision vs. hockey stick incision, respectively) and in level $\mathrm{V}$ was 6.36 vs. $5.63(P=0.597)$.

Scores for VSS and subjective sensory change in the neck area were not significantly different between the two groups (Table 4). Total cosmetic satisfaction score was significantly lower (more satisfied) in the transverse incision group than in the hockey stick group $(6.35 \pm$ 5.07 vs. $9.08 \pm 4.81 ; P=0.029)$ and was also significantly lower for overall satisfaction with the scar $(1.54 \pm 1.06$ vs. $2.29 \pm 0.86 ; P=0.003)$ and satisfaction with the neck contour $(1.43 \pm 0.91$ vs. $2.08 \pm 0.88 ; P=0.004)$. Scores for scar consciousness and sensory change were also lower in the transverse incision group than in the hockey stick group; although, this was not statistically significant.

\section{Discussion}

Improving quality of life has been a major goal in the treatment of differentiated thyroid carcinoma, as patients have a good prognosis [13, 14]. In general, patients are deeply concerned about a visible scar in the neck [11]. Recently, remote-access incisions, such as the transaxillary, axillo-breast, and postauricular facelift incisions, have been developed for LND of thyroid cancer, with the aim of concealing the scar in the neck area, and thereby demonstrating the interest of both surgeons and patients in cosmetic results $[6,15-17]$. Even in the conventional transcervical approach, there have been attempts to reduce the scar length or to design a less noticeable skin incision for better cosmesis [9].

Various incisions are used for transcervical LND in the treatment of thyroid cancer with lateral compartment lymph node metastasis. A hockey stick incision was introduced by Lahey et al. in 1940 [18]. The hockey stick incision enables good exposure of the parotid area and neck levels I and II (Fig. 1b). However, a vertical portion of the incision lateral to the sternocleidomastoid muscle crosses the Langer's tension line. To avoid the vertical incision, MacFee suggested parallel transverse incisions for radical neck dissection in 1951 [19]. However, this approach has the disadvantages of limited exposure and increased operative time, especially in patients with short and/or obese necks [20, 21]. L-shaped hockey stick incisions and modified MacFee incisions have traditionally been used to expose the upper neck, including levels I and II, during LND for thyroid cancer. However, smaller incisions or single transverse incisions are being utilized more frequently as a result of increasing concerns for better cosmesis. The development of energy devices, such as the ultrasonic scalpel, has enabled surgeons to dissect the upper neck relatively easily without the need for a large incision. An extended single transverse incision, which is the extension of a transverse incision for thyroidectomy, does not cross the skin-tension line, and thus, good cosmetic results are anticipated. However, there have been concerns that this approach can result in incomplete excision and worse oncological outcomes [7]. In particular, surgeons may have concerns about incomplete dissection of level II using this approach.

In our institution, we use either an L-shaped hockey stick incision or a single low transverse incision for total thyroidectomy and concomitant lateral compartment neck dissection. Because the hockey stick incision invades the resting skin-tension line, we recently started to favor the low transverse incision. In our institution, the low transverse incision is placed one finger-breadth superior to the suprasternal notch; this is more inferior to the modified extended Kocher incision, which is at the level of cricoid cartilage [7]. The advantage of the 
Table 2 Comparison of surgical outcomes of patients with low transverse lateral incision and hockey stick incision

\begin{tabular}{|c|c|c|c|}
\hline Parameter & $\begin{array}{l}\text { Transverse } \\
\text { Incision group } \\
n=62\end{array}$ & $\begin{array}{l}\text { Hockey stick } \\
\text { Incision group } \\
n=35\end{array}$ & $P$ value \\
\hline Total thyroidectomy & $62(100 \%)$ & 35 (100\%) & NA \\
\hline Central neck dissection & & & .604 \\
\hline Unilateral & $5(8.1 \%)$ & $3(8.6 \%)$ & \\
\hline Bilateral & $57(91.9 \%)$ & $32(91.4 \%)$ & \\
\hline Lateral selective neck dissection & & & .132 \\
\hline Level II, III, IV, V & $44(71.0 \%)$ & $29(82.9 \%)$ & \\
\hline Level II, III, IV & $11(17.7 \%)$ & $5(14.6 \%)$ & \\
\hline Level III, IV, V & $7(11.3 \%)$ & $1(2.9 \%)$ & \\
\hline Total operative time (min) & $273 \pm 79$ & $270 \pm 90$ & .849 \\
\hline SND $(I I-V)$ & $276 \pm 94$ & $290 \pm 83$ & .504 \\
\hline SND (II-IV)/SND (III-V) & $230 \pm 48$ & $239 \pm 65$ & .746 \\
\hline Amount of drainage $(\mathrm{mL})$ & $386 \pm 215$ & $410 \pm 233$ & .632 \\
\hline \multicolumn{4}{|l|}{ Complication } \\
\hline Hypoparathyroidism & & & .916 \\
\hline Transient & $24 / 62(38.7 \%)$ & 13/35 (37.1\%) & \\
\hline Permanent & $1 / 62(1.6 \%)$ & $1 / 35(2.9 \%)$ & \\
\hline Vocal cord paralysis & & & .619 \\
\hline Transient & $6 / 62(9.7 \%)$ & $4 / 35(11.4 \%)$ & \\
\hline Permanent & $1 / 62(1.6 \%)$ & 0/35 (0\%) & \\
\hline Hematoma & $3 / 62(4.8 \%)$ & $2 / 35(5.7 \%)$ & .597 \\
\hline Seroma & $2 / 62(3.2 \%)$ & $2 / 35(5.7 \%)$ & .618 \\
\hline Chyle leakage & $2 / 62(3.2 \%)$ & 0/35 (0\%) & .534 \\
\hline Spinal accessory nerve injury & 0 & 0 & NA \\
\hline Horner syndrome & 0 & 0 & NA \\
\hline Brachial plexus injury & 0 & 0 & NA \\
\hline Phrenic nerve injury & 0 & 0 & NA \\
\hline Wound infection & 0 & $2 / 35(3.2 \%)$ & .534 \\
\hline Skin necrosis & 0 & 0 & NA \\
\hline Follow-up period (month) & $60.6 \pm 26.3$ & $58.0 \pm 24.9$ & 640 \\
\hline RAl ablation & $60 / 62(96.8 \%)$ & $31 / 35(88.6 \%)$ & .184 \\
\hline Dose of RAl ablation (mCi) & $153.4 \pm 32.7$ & $161.1 \pm 34.1$ & .344 \\
\hline Stimulated $\mathrm{Tg}$ at the first RAI (ng/ml) & $7.35 \pm 12.0$ & $6.78 \pm 9.70$ & .820 \\
\hline Stimulated $\mathrm{Tg}$ at diagnostic WBS after RAI (ng/ml) & $1.02 \pm 1.62$ & $1.15 \pm 2.25$ & .741 \\
\hline Uptake outside thyroid bed at WBS after RAI & $0 / 60$ & $1 / 31(3.2 \%)$ & .340 \\
\hline
\end{tabular}

Values in the table are mean $\pm \mathrm{SD}$, unless indicated otherwise

SND selective neck dissection, NA not applicable, $R A$ I radioactive iodine, $T g$ thyroglobulin, WBS ${ }^{131}$ I whole-body scan, SD standard deviation

low transverse incision over the modified extended Kocher incision is that the scar can be concealed by clothes with collars.

To date, cosmetic and functional results of the low transverse incision approach have not yet been evaluated thoroughly. One preliminary study compared the cosmetic results of the modified extended Kocher incision and the apron incision, with a short follow-up period
[7]. However, the study analyzed only a limited number of factors, including the presence of hypertrophic scarring and stretching, the use of silicone gel therapy, and scar revision [7]. To our knowledge, the current study is the first to evaluate the scar resulting from a single low transverse incision in the treatment of PTC with lateral neck metastasis. We analyzed the objective and subjective, cosmetic and functional results of the low 
Table 3 Number of harvested and metastatic lymph nodes in patients who received lateral neck dissection

\begin{tabular}{|c|c|c|c|c|}
\hline Parameter & & $\begin{array}{l}\text { Transverse } \\
\text { Incision group } \\
n=62\end{array}$ & $\begin{array}{l}\text { Hockey stick } \\
\text { Incision group } \\
n=35\end{array}$ & $P$ value \\
\hline \multirow[t]{3}{*}{ Total } & Harvested LN, $n$ & $36.67 \pm 19.99$ & $32.06 \pm 16.34$ & .263 \\
\hline & Metastatic LN, $n$ & $10.29 \pm 7.61$ & $8.87 \pm 6.73$ & .378 \\
\hline & Ratio (\%) & $30.74 \pm 17.70$ & $28.30 \pm 20.55$ & .550 \\
\hline \multirow[t]{3}{*}{ Central (level VI) } & Harvested LN, $n$ & $10.07 \pm 8.45$ & $7.83 \pm 6.79$ & .214 \\
\hline & Metastatic LN, $n$ & $5.05 \pm 4.71$ & $3.60 \pm 2.84$ & .126 \\
\hline & Ratio (\%) & $52.94 \pm 31.62$ & $61.08 \pm 34.57$ & .271 \\
\hline \multirow[t]{3}{*}{ Lateral } & Harvested LN, $n$ & $27.70 \pm 15.49$ & $29.29 \pm 10.97$ & .631 \\
\hline & Metastatic LN, $n$ & $5.65 \pm 4.09$ & $6.52 \pm 4.89$ & .393 \\
\hline & Ratio (\%) & $23.98 \pm 17.33$ & $22.87 \pm 15.90$ & .777 \\
\hline \multirow[t]{3}{*}{ Level II } & Harvested LN, $n$ & $9.82 \pm 6.12$ & $9.63 \pm 4.49$ & .885 \\
\hline & Metastatic LN, $n$ & $2.42 \pm 1.82$ & $2.33 \pm 2.05$ & .848 \\
\hline & Ratio (\%) & $33.63 \pm 32.72$ & $24.83 \pm 22.99$ & .243 \\
\hline \multirow[t]{3}{*}{ Level III } & Harvested LN, $n$ & $7.96 \pm 4.72$ & $8.48 \pm 3.20$ & .609 \\
\hline & Metastatic LN, $n$ & $2.06 \pm 1.89$ & $2.11 \pm 2.04$ & .906 \\
\hline & Ratio (\%) & $28.49 \pm 27.72$ & $24.69 \pm 23.86$ & .545 \\
\hline \multirow[t]{3}{*}{ Level IV } & Harvested LN, $n$ & $8.13 \pm 4.96$ & $8.29 \pm 6.88$ & .899 \\
\hline & Metastatic LN, $n$ & $1.67 \pm 1.55$ & $1.89 \pm 2.15$ & .595 \\
\hline & Ratio (\%) & $23.05 \pm 22.23$ & $26.15 \pm 31.04$ & .636 \\
\hline \multirow[t]{3}{*}{ Level V } & Harvested LN, $n$ & $6.36 \pm 5.21$ & $5.63 \pm 4.48$ & .597 \\
\hline & Metastatic LN, $n$ & $0.36 \pm 0.86$ & $0.63 \pm 0.83$ & .258 \\
\hline & Ratio (\%) & $7.99 \pm 22.19$ & $11.98 \pm 17.38$ & .489 \\
\hline
\end{tabular}

All values in the table are mean \pm SD

$L N$ lymph node, $n$ number, SD standard deviation

Table 4 Comparison of cosmetic satisfaction and sensory change scores in patients who underwent lateral neck dissection

\begin{tabular}{|c|c|c|c|}
\hline Parameter & $\begin{array}{l}\text { Transverse } \\
\text { Incision group } \\
n=62\end{array}$ & $\begin{array}{l}\text { Hockey stick } \\
\text { Incision group } \\
n=35\end{array}$ & $P$ value \\
\hline$\overline{\text { Vancouver Scar Scale (VSS) Score }}{ }^{a}$ & $0.50 \pm 0.93$ & $0.45 \pm 0.52$ & .881 \\
\hline Total Cosmetic Satisfaction Score ${ }^{a}$ & $6.35 \pm 5.07$ & $9.08 \pm 4.81$ & $.029^{*}$ \\
\hline Scar satisfaction & $1.54 \pm 1.06$ & $2.29 \pm 0.86$ & $.003^{*}$ \\
\hline Contour satisfaction & $1.43 \pm 0.91$ & $2.08 \pm 0.88$ & $.004^{*}$ \\
\hline Scar noticeable & $0.88 \pm 1.02$ & $1.08 \pm 1.01$ & .394 \\
\hline Try to conceal the scar & $0.89 \pm 1.04$ & $1.16 \pm 1.09$ & .287 \\
\hline Scar influences choice of clothes & $0.89 \pm 1.10$ & $1.25 \pm 1.18$ & .196 \\
\hline Frequency of thinking about scar & $0.91 \pm 0.93$ & $1.21 \pm 0.88$ & .182 \\
\hline Sensory Change Score ${ }^{a}$ & $1.71 \pm 1.17$ & $2.01 \pm 1.13$ & .431 \\
\hline Survey period (months after surgery) ${ }^{\mathrm{b}}$ & $16.4 \pm 3.4$ & $18.2 \pm 2.1$ & .137 \\
\hline
\end{tabular}

All values in the table are mean $\pm S D$

* $P<0.05$

aLower scores mean greater satisfaction

${ }^{b}$ VSS, cosmetic satisfaction, and sensory change were evaluated on the same day 
transverse incision compared to the hockey stick incision using a validated objective scar measurement (the VSS); a subjective scar assessment for cosmetic satisfaction, scar consciousness, and sensory change; and surgical outcome measures including the number of harvested and metastatic lymph nodes at each neck level.

In the current study, there were no significant differences in operative time, complication rates, or oncological outcomes between the transverse incision and hockey stick incision groups. The number of lymph nodes harvested from the transverse incision group at neck levels II and V and the total lateral compartment were 9.8, 6.4, and 27.7, respectively. These values are in accordance with the number of lymph nodes harvested from the hockey stick incision group (9.6, 5.6, and 29.3, respectively) and the results from a published data (mean $8.3-10.3,6.2-6.6$, and 31.1-31.5, respectively) [22-24]. In addition, the mean number of metastatic lymph nodes in the transverse incision group at neck levels II and V and the total lateral compartment were 2.4, 0.4, and 5.7, respectively, which were similar to both the mean number of metastatic lymph nodes in the hockey stick incision group (2.3, 0.6, and 6.5) and the published data (1.2-2.7, 0.3-1.9, and 4.6-4.8) [22-24]. These results suggest that surgical accessibility to the upper neck level is comparable between the single low transverse incision and the hockey stick incision in LND (Fig. 2b).

Objectively, the mean VSS score in the transverse incision group was 0.50 , with no statistical difference to the VSS score (mean 0.45) in the hockey stick incision group. These scores are lower than those reported after transcervical thyroidectomy without LND in a study by O'Connell et al. (VSS score mean 2.5) [9]. This difference might be attributable to patient factors and/or a difference in observer or surgical technique, such as suture tension.

Subjectively, patient satisfaction with scar and neck contour was significantly higher in the transverse incision group. Also, scar consciousness (measured by whether the patient thinks others notice the scar, whether the patient tries to conceal the scar, whether the scar influences the patient's choice of clothes, and how often the patient thinks about the scar) was less in the transverse incision group; although, it did not reach statistical significance. Taken together, these results confirm the superior cosmesis of the low single transverse incision, which is considered to be the main advantage of lateral neck dissection.

There are some limitations to the current study. This study lacks randomization for the two incision approaches, and the sample size was small. Recently, we performed more cases of transverse incision than hockey stick incision, due to its cosmetic superiority. However, the mean follow-up periods are not significantly different between the two groups, and all the neck dissections in this study were performed after the period of learning curve of the surgeon (K.T.). A future randomized study including a larger number of patients is necessary to overcome these limitations. In addition, the questionnaire for cosmetic satisfaction and scar consciousness has not yet been validated. However, the scores for cosmetic satisfaction and scar consciousness correlated significantly with VSS in our previous study $[11,25]$. Another limitation is that the study population included only Koreans. It is well known that ethnicity influences the formation of hypertrophic scars and keloids [8]. Therefore, the results of this study cannot be easily translated to patients in other ethnic groups and in other countries.

\section{Conclusions}

In conclusion, a single low transverse incision for LND and total thyroidectomy provides equivalent surgical outcomes and superior cosmetic outcomes compared to those in a hockey stick incision in the treatment of PTC with lateral compartment lymph node metastasis.

\section{Abbreviations \\ LND: Lateral neck dissection; MRND: Modified radical neck dissection; \\ N: Node; PTC: Papillary thyroid carcinoma; RAl: Radioactive iodine; T: Tumor; TG: Thyroglobulin; TNM: Tumor, node, metastasis; TSH: Thyroid-stimulating hormone; VSS: Vancouver Scar Scale}

\section{Acknowledgements}

Not applicable.

\section{Funding}

The authors received no financial support for the research, authorship, and/ or publication of this article.

\section{Availability of data and materials}

All relevant data generated or analyzed during this study are included in this paper

\section{Authors' contributions}

CMS and KT are involved in the conception and design of the study. ISK is involved in the acquisition of the data. CMS, YBJ, JYL, DSK, and KT are involved in the analysis and interpretation of the data. CMS is involved in drafting the article. YBJ, ISK, DSK, and KT are involved in the manuscript revision. All authors read and approved the final manuscript.

\section{Competing interests}

The authors declare that they have no competing interests.

Consent for publication

Not applicable.

Ethics approval and consent to participate

Our study has been performed in accordance with the Declaration of Helsinki. This study was approved by the Institutional Review Board of Hanyang University Hospital (IRB No. HYUH 2014-03-010-003).

\section{Publisher's Note}

Springer Nature remains neutral with regard to jurisdictional claims in published maps and institutional affiliations. 


\section{Author details}

'Department of Otolaryngology-Head and Neck Surgery, College of Medicine, Hanyang University, 222 Wangsimni-ro, Seongdong-gu, Seou 04763, South Korea. ${ }^{2}$ Department of Radiology, College of Medicine, Hanyang University, 222 Wangsimniro, Seongdong-Gu, Seoul 04763, South Korea. ${ }^{3}$ Department of Internal Medicine, College of Medicine, Hanyang University, 222 Wangsimniro, Seongdong-Gu, Seoul 04763, South Korea.

Received: 28 November 2016 Accepted: 23 April 2017

Published online: 04 May 2017

\section{References}

1. Morris LG, Sikora AG, Tosteson TD, Davies L. The increasing incidence of thyroid cancer: the influence of access to care. Thyroid. 2013;23(7):885-91.

2. Park JY, Koo BS. Individualized optimal surgical extent of the lateral neck in papillary thyroid cancer with lateral cervical metastasis. Eur Arch Otorhinolaryngol. 2014;271(6):1355-60.

3. Park CH, Song CM, Ji YB, Pyo JY, Yi KJ, Song YS, Park YW, Tae K. Significance of the extracapsular spread of metastatic lymph nodes in papillary thyroid carcinoma. Clin Exp Otorhinolaryngol. 2015;8(3):289-94.

4. Cooper DS, Doherty GM, Haugen BR, Kloos RT, Lee SL, Mandel SJ, Mazzaferri EL, Mclver B, Pacini F, Schlumberger M, Sherman SI, Steward DL, Tuttle RM. Revised American Thyroid Association Management Guidelines for patients with thyroid nodules and differentiated thyroid cancer. Thyroid. 2009;19(11):1167-214.

5. Keum HS, Ji YB, Kim JM, Jeong JH, Choi WH, Ahn YH, Tae K. Optimal surgical extent of lateral and central neck dissection for papillary thyroid carcinoma located in one lobe with clinical lateral lymph node metastasis. World J Surg Oncol. 2012;10:221.

6. Tae K, Ji YB, Song CM, Min HJ, Lee SH, Kim DS. Robotic lateral neck dissection by a gasless unilateral axillobreast approach for differentiated thyroid carcinoma: our early experience. Surg Laparosc Endosc Percutan Tech. 2014;24(4):e128-32.

7. Simo R, Nixon I, Tysome JR, Balfour A, Jeannon JP. Modified extended Kocher incision for total thyroidectomy with lateral compartment neck dissection-a critical appraisal of surgical access and cosmesis in 31 patients. Clin Otolaryngol. 2012;37(5):395-8.

8. Son D, Harijan A. Overview of surgical scar prevention and management. J Korean Med Sci. 2014;29(6):751-7.

9. O'Connell DA, Diamond C, Seikaly H, Harris JR. Objective and subjective scar aesthetics in minimal access vs conventional access parathyroidectomy and thyroidectomy surgical procedures: a paired cohort study. Arch Otolaryngol Head Neck Surg. 2008;134(1):85-93.

10. Draaijers $\amalg$, Tempelman FR, Botman YA, Tuinebreijer WE, Middelkoop E, Kreis RW, van Zuijlen PP. The patient and observer scar assessment scale: a reliable and feasible tool for scar evaluation. Plast Reconstr Surg. 2004;113(7):1960-7.

11. Ji YB, Song CM, Bang HS, Lee SH, Park YS, Tae K. Long-term cosmetic outcomes after robotic/endoscopic thyroidectomy by a gasless unilateral axillo-breast or axillary approach. J Laparoendosc Adv Surg Tech A. 2014;24(4):248-53.

12. Song CM, Ji YB, Bang HS, Park CW, Kim H, Tae K. Long-term sensory disturbance and discomfort after robotic thyroidectomy. World J Surg 2014;38(7):1743-8.

13. Hoftiizer HC, Heemstra KA, Corssmit EP, van der Klaauw AA, Romijn JA, Smit JW. Quality of life in cured patients with differentiated thyroid carcinoma. J Clin Endocrinol Metab. 2008:93(1):200-3.

14. Song CM, Ji YB, Bang HS, Park CW, Kim DS, Tae K. Quality of life after robotic thyroidectomy by a gasless unilateral axillary approach. Ann Surg Oncol. 2014;21:4188-94.

15. Kang SW, Lee SH, Ryu HR, Lee KY, Jeong JJ, Nam KH, Chung WY, Park CS. Initial experience with robot-assisted modified radical neck dissection for the management of thyroid carcinoma with lateral neck node metastasis. Surgery. 2010;148:1214-21.

16. Song CM, Park JS, Park W, Ji YB, Cho SH, Tae K. Feasibility of charcoal tattooing for localization of metastatic lymph nodes in robotic selective neck dissection for papillary thyroid carcinoma. Ann Surg Oncol. 2015;22:669-75.

17. Kim BS, Kang KH, Park SJ. Robotic modified radical neck dissection by bilateral axillary breast approach for papillary thyroid carcinoma with lateral neck metastasis. Head Neck. 2015;37:37-45.
18. Lahey FH, Hare HF, Warren S. Carcinoma of the thyroid. Ann Surg. 1940:112:977-1005.

19. Macfee WF. The surgical treatment of carcinoma of the thyroid gland, with special reference to metastasis. Surg Clin North Am. 1953:361-387.

20. Omura S, Bukawa H, Kawabe R, Aoki S, Fujita K. Comparison between hockey stick and reversed hockey stick incision: gently curved single linear neck incisions for oral cancer. Int J Oral Maxillofac Surg. 1999;28:197-202.

21. Dancey AL, Srivastava S. Experience with the modified hockey stick incision for block dissection of neck. J Plast Reconstr Aesthet Surg. 2006;59:1276-9.

22. Lee J, Sung TY, Nam KH, Chung WY, Soh EY, Park CS. Is level Ilb lymph node dissection always necessary in N1b papillary thyroid carcinoma patients? World J Surg. 2008:32:716-21.

23. Koo BS, Yoon YH, Kim JM, Choi EC, Lim YC. Predictive factors of level IIb lymph node metastasis in patients with papillary thyroid carcinoma. Ann Surg Oncol. 2009;16:1344-7.

24. Kim WS, Koh YW, Byeon HK, Park YM, Chung HJ, Kim ES, Lee EJ, Park SC, Choi EC. Robot-assisted neck dissection via a transaxillary and retroauricular approach versus a conventional transcervical approach in papillary thyroid cancer with cervical lymph node metastases. J Laparoendosc Adv Surg Tech A. 2014:24:367-72.

25. Tae $\mathrm{K}$, Ji YB, Jeong JH, Lee SH, Jeong MA, Park CW. Robotic thyroidectomy by a gasless unilateral axillo-breast or axillary approach: our early experiences. Surg Endosc. 2011;25:221-8.

\section{Submit your next manuscript to BioMed Central and we will help you at every step:}

- We accept pre-submission inquiries

- Our selector tool helps you to find the most relevant journal

- We provide round the clock customer support

- Convenient online submission

- Thorough peer review

- Inclusion in PubMed and all major indexing services

- Maximum visibility for your research

Submit your manuscript at www.biomedcentral.com/submit
) Biomed Central 